\title{
Symptoms and cholinesterase activity among rural residents living near cotton fields in Nicaragua
}

\author{
Matthew Keifer, Francisca Rivas, Jai Dong Moon, Harvey Checkoway
}

\begin{abstract}
Objectives-To explore whether symptoms resulted from pesticide spray drift on residentially exposed populations in rural Nicaragua.

Methods-100 residents, each 10 years of age or older, were randomly selected from a Nicaraguan community surrounded by actively sprayed cotton fields (the exposed community) and from a socioeconomically similar community far from agricultural spraying (the control community). Subjects working with pesticides were excluded, and the study was conducted at the end of the 1990 cotton spraying season (August-December). Demographic information, exposure questions, and prevalence of 11 acute symptoms and 17 chronic symptoms were gathered from a structured interview. Finger stick erythrocyte cholinesterase (AChE) was measured with a portable colorimeter. Acute symptoms were grouped according to their previously known associations with cholinesterase (ChE) inhibitors into four ordinal categories (asymptomatic, non-specific, possible, probable).
\end{abstract}

Results-Residents from the exposed community were significantly more likely to report recently sighting a spray plane near their community, exposure to pesticide from drift, crossing recently sprayed fields, eating home grown food, and feeling ill after drift exposure. The mean AChE value was significantly lower for residents of the exposed community (4.9 $v$ $5.3 \mathrm{IU} / \mathrm{dl})$. The proportion of subjects complaining of one or more chronic or acute symptoms was significantly higher for the exposed community $(87 \%)$ than for the controls (53\%). Odds ratios for residents in the exposed community, by symptom categories, were non-specific 1.6 (95\% confidence interval (95\% CI) 0.8 to $3 \cdot 2)$, possible $4 \cdot 1(95 \%$ CI $1 \cdot 7$ to $10 \cdot 2)$, and probable $9.93(95 \%$ CI 2.9 to 34.4$)$.

Conclusion-These findings indicate a strong association between exposure to aerial pesticides and symptoms. This study should be replicated with more quantitative exposure measures, for if confirmed, the results have relevance for millions in rural communities worldwide.

(Occup Environ Med 1996;53:726-729)

Keywords: pesticides; organophosphates; neurotoxicity
Synthetic pesticides have been used intensively for control of cotton pests in many countries since the end of the second world war. Before Nicaragua's recent agroeconomic changes, large quantities of pesticides were applied to cotton fields by aerial applications. ${ }^{12}$ Many instances of poisonings of workers have been reported from Nicaragua and other Central American countries, particularly by the widely used cholinesterase (ChE) inhibiting carbamates and organophosphate insecticides. ${ }^{3-6}$ Rural communities in Nicaragua are often located very near actively cultivated fields, and in recent years the Nicaraguan Ministry of Health has received numerous complaints from rural residents of exposure from drifting pesticide. Previous community studies of aerial exposure from pesticide drift have shown mixed symptoms. ${ }^{7-14}$ To explore possible effects of chronic drift exposure, we assessed prevalence of symptoms and erythrocyte cholinesterase (AChE) concentrations in a cross sectional study of residentially exposed and unexposed populations in Nicaragua. We focused on symptoms and effects of $\mathrm{ChE}$ inhibitors because these are generally the most acutely toxic chemicals applied to Nicaraguan cotton, ${ }^{13}$ the symptoms associated with acute overexposure are well characterised, ${ }^{15}$ and a validated field method for AChE measurement was available. ${ }^{16}$

\section{Materials and methods}

In early December, at the end of the 1990 cotton pesticide application season (August to December) in northwestern Nicaragua, one rural village (the exposed community) and one urban neighbourhood (the control community), were identified for our cross sectional study. The exposed community was chosen because it was near the cotton fields that were being sprayed with aerial pesticide. About 2 $\mathrm{km}$ from the outskirts of the region's largest city, Leon, the community is a densely populated rectangle, limited on three sides by growing cotton fields. A single perimeter road about 10 metres wide separates the houses on the edge of the village from the growing cotton. A school and playground border the fourth side, with a ravine and fallow land beyond. Agricultural pesticide spray planes often fly over the community during spraying operations on nearby cotton fields. The control community was chosen for its similar socioeconomic status. It is an urban community, located within Leon, about $0.5 \mathrm{~km}$ from any active agricultural land. The local chapter 
of Movmiento Comunal, a nationwide community based organisation, advised us in the selection of a socioeconomically comparable community, cooperated with us in providing community rosters, and assisted in the recruitment of study participants. Names were randomly chosen from the community roster and community members were approached and asked to participate by neighbourhood organisers. Participants received no incentives for participation. From each site we limited our sample to 100 community members of either sex who were 10 years of age or older at the time of the survey. Subjects who worked in contact with pesticides in the preceding three months were excluded either during name selection (some were known to the community organisers as pesticide applicators), or during recruitment. People who were selected from the list but were excluded or refused to participate were replaced by a subsequent random selection.

A pretested structured interview questionnaire elicited demographic, exposure, and symptom information. The questionnaire was composed of questions adapted from other questionnaires used for previous pesticide investigations by the local health department and the National Autonomous University of Nicaragua, Leon. Eleven questions asked whether specific acute symptoms had occurred during the 15 days before the interview. Also included was a 17 question Spanish language adaptation of the questionnaire 16 (Q-16). ${ }^{1718}$ These questions were asked without a specified time window. The Q-16 was developed and validated in Sweden and was designed to elicit chronic neurobehavioural symptoms from populations exposed to neurotoxicants. At the time of our study the 17 questions had been translated into Spanish by local investigators who were in the process of validating its use in Nicaragua. The complete interview questionnaire was field tested for comprehensibility one month before data collection and was used at the same time as AChE testing by two Nicaraguan physicians.

The AChE testing was conducted in the two community health clinics during a working day in early December. A single portable colorimeter system was used for all testing (model 176 EQM). Blood was obtained by deep lancet finger stick sampling after cleaning the finger with dilute sodium hydroxide and isopropyl alcohol. Blood $(25 \mu \mathrm{l})$ was aspirated with a disposable tip pipette and mixed with $100 \mu \mathrm{l}$ of buffer solution. One fifth $(25 \mu \mathrm{l})$ of this solution was then transferred to a $1 \mathrm{~cm}$ path length plastic sample cuvette and mixed with $2 \mathrm{ml}$ of a mixture of sterile water, thiocholine, and dithionitrobenzene (DTNB), prepared before the start of testing. The change in absorbence of the sample over the two minutes was used to calculate temperature corrected AChE activity. Single samples were run for each participant. Examiner blinding was not possible due to the location of the testing and we did not attempt to blind subjects to the purpose of the study.

Before the start of analysis, we organised the acute symptoms queried in the interview into clusters according to symptom specificity and previously reported association with exposure to $\mathrm{ChE}$ inhibitor. ${ }^{51114151921}$ As low level chronic exposure was of concern, the more traditional acute toxicity categories mild, moderate, and severe, such as those developed by Namba $e t a l^{15}$ based on acute pesticide intoxications, could not be used directly. Instead, the symptom clusters developed for the analysis were ordinal, ranging from asymptomatic to probable. The probable symptom cluster was composed of symptoms which, if present together with overexposure to $\mathrm{ChE}$, would probably be diagnosed by a knowledgeable clinician as representing an overexposure to ChE inhibitors. Table 1 shows the symptom profiles of each category.

We analysed the 17 symptom questions from the modified Q-16 $6^{1718}$ separately from the symptom questions more likely to represent acute exposure. Odds ratios and associated $95 \%$ confidence intervals ( $95 \%$ CIs) were calculated to estimate effects related to residence. Results are presented with the asymptomatic group and alternatively with the non-specific symptom group as the control group. Data were analysed with BMDP software. ${ }^{22}$ Analyses of variance and covariance were used to compare the demographic characteristics and the mean $\mathrm{ChE}$ concentrations between communities. The $\chi^{2}$ test with continuity correction and Fisher's exact test were used to compare the response rates for demographic and exposure questions between exposed and control communities. Polychotomous logistic regression analysis was used to evaluate the association of symptom category with exposure community. ${ }^{23}$ Covariates included in the analysis were age (continuous), sex, current smoking, and recent drinking status (dichotomous).

\section{Results}

The socioeconomic comparability of the exposure and control communities was confirmed before beginning the study by consulting with local Ministry of Health officials and with the local branch of the Movimiento Comunal, which regularly monitored economic and political developments locally and nationally.

Table 1 Symptom categories of acute symptoms and inclusion criteria

\begin{tabular}{|c|c|}
\hline Symptom category & Inclusion criteria \\
\hline $\begin{array}{l}\text { Asymptomatic } \\
\text { Non-specific }\end{array}$ & $\begin{array}{l}\text { No reported symptoms } \\
\text { One or two non-specific symptoms }{ }^{\star} \text {, or } \\
\text { one specific symptom and no non- } \\
\text { specific symptoms }\end{array}$ \\
\hline Possible & $\begin{array}{l}\text { Three or more non-specific symptoms, or } \\
\text { one or two non-specific symptoms plus } \\
\text { one specific symptom, or one or no } \\
\text { non-specific symptoms plus two } \\
\text { specific symptoms }\end{array}$ \\
\hline Probable & $\begin{array}{l}\text { Three or more non-specific symptoms } \\
\text { plus one specific symptom, or two or } \\
\text { more non-specific symptoms plus two } \\
\text { specific symptoms, or three specific } \\
\text { symptoms }\end{array}$ \\
\hline
\end{tabular}

*Non-specific symptoms are vomiting, nausea, headache, weakness, tremor, abdominal pain, diarrhoea, and dyspnoea. †Specific symptoms are blurry vision, excessive salivation, and fasciculations. 
One hundred subjects from each location were interviewed and tested for AChE. Five community members from the exposed community and 10 from the control community were excluded because they had recent occupational exposure to pesticides or they refused to participate after initial recruitment. The participants were mostly female (58\% exposed, $63 \%$ controls) due to the fact that testing was done during daylight working hours when many men were working, and people exposed to pesticides (principally men) were excluded from the sample. There were no significant differences in mean age (26 exposed $v 29$ controls, mean difference $95 \% \mathrm{CI}-2.4$ to 7.9 ), use of alcohol (10\% v 10\%), or use of tobacco (10\% exposed $v \quad 6.7 \%$ controls). Recent malaria was reported in two people, one from each community. Due to the fact that the exposed community is a relatively recent settlement and the control community is an older urban neighbourhood, there were significant differences in the years of residence by location $(10.6$ exposed $v 20 \cdot 1$ control, mean difference $95 \%$ CI 6.0 to 12.9 ).

All responding members from the exposed community reported sighting spray planes fly by their community in the preceding 15 days. Most (85\%) reported three or more sightings and $23(24 \%)$ reported daily or more frequent sightings. No members of the control commu-

Table 2 Percentage reporting symptoms and odds ratios (ORs) for residence in exposed community

\begin{tabular}{|c|c|c|c|}
\hline \multirow[b]{2}{*}{ Reported symptoms } & \multicolumn{2}{|c|}{ Complaint rate (\%) } & \multirow[b]{2}{*}{ OR $(95 \% C I)$} \\
\hline & $\begin{array}{l}\text { Exposed } \\
(n=98-100)\end{array}$ & $\begin{array}{l}\text { Unexposed } \\
(n=97-100)\end{array}$ & \\
\hline \multicolumn{4}{|l|}{ Acute symptoms: } \\
\hline Vomiting & $5 \cdot 1$ & $7 \cdot 1$ & $0.69(0.21$ to 2.27$)$ \\
\hline Nausea & $28 \cdot 3$ & $10 \cdot 1$ & $3.51(1.59$ to 7.74$)$ \\
\hline Headache & 55.0 & $34 \cdot 3$ & $2.34(1.31$ to $4 \cdot 16)$ \\
\hline Weakness & $26 \cdot 5$ & $3 \cdot 1$ & $11.32(3.27$ to 38.89$)$ \\
\hline Tremor & $12 \cdot 1$ & $2 \cdot 0$ & $6.62(1.43$ to 30.41$)$ \\
\hline Abdominal pain & $25 \cdot 3$ & $9 \cdot 2$ & $3.34(1.46$ to 7.64$)$ \\
\hline Diarrhoea & $9 \cdot 1$ & $7 \cdot 1$ & $1.30(0.46$ to 3.66$)$ \\
\hline Dyspnoea & $17 \cdot 2$ & $3 \cdot 1$ & $6.57(1.84$ to 23.20$)$ \\
\hline Blurry vision & $17 \cdot 2$ & $12 \cdot 1$ & $1.50(0.67$ to 3.36$)$ \\
\hline Excessive salivation & $15 \cdot \overline{2}$ & $7 \cdot 1$ & $2.35(0.91$ to 6.07$)$ \\
\hline Fasciculation & $12 \cdot 1$ & $0 \cdot 0$ & $\infty^{\star}$ \\
\hline \multicolumn{4}{|l|}{ Modified Q-16 questions } \\
\hline Are you forgetful? & $15 \cdot 2$ & $7 \cdot 1$ & $4.28(2.16$ to 8.45$)$ \\
\hline Family think you forgetful & $24 \cdot 0$ & 6.0 & $4.95(1.91$ to 12.73$)$ \\
\hline Often return to check things & $40 \cdot 0$ & $6 \cdot 0$ & $10 \cdot 44(4 \cdot 15$ to $26 \cdot 14)$ \\
\hline Poor concentration & $27 \cdot 0$ & $2 \cdot 0$ & $18.12(4.14$ to $78 \cdot 65)$ \\
\hline Angered easily & $28 \cdot 0$ & $4 \cdot 0$ & $9.33(3.11$ to 27.82$)$ \\
\hline Depressed & $25 \cdot 0$ & $3 \cdot 0$ & 10.67 (3.08 to 36.66$)$ \\
\hline Tired & $25 \cdot 0$ & $5 \cdot 0$ & $6.33(2.30$ to 17.35$)$ \\
\hline Palpitation & $23 \cdot 0$ & $6 \cdot 0$ & $4.68(1.80$ to 12.06$)$ \\
\hline Chest pressure & $29 \cdot 0$ & $5 \cdot 0$ & $7.76(2.84$ to 21.04$)$ \\
\hline Frequent headache & $50 \cdot 5$ & $13 \cdot 0$ & $6.83(3.36$ to 13.80$)$ \\
\hline Feel like falling & $39 \cdot 0$ & $6 \cdot 0$ & $10.02(3.98$ to 25.06$)$ \\
\hline Numbness in body part & $29 \cdot 0$ & $3 \cdot 0$ & $13.21(3.84$ to 45.06$)$ \\
\hline Problem buttoning shirt & $8 \cdot 2$ & $1 \cdot 0$ & $8.71(1.05$ to 70.97$)$ \\
\hline Lost sensation somewhere & $4 \cdot 0$ & 0.0 & $\infty^{\star}$ \\
\hline More saliva than normal & $10 \cdot 1$ & $1 \cdot 0$ & $11.12(1.38$ to 88.82$)$ \\
\hline Sleeping problem & $27 \cdot 0$ & $15 \cdot 0$ & $1.10(1.03$ to 4.26$)$ \\
\hline Awakening suddenly & $31 \cdot 0$ & $14 \cdot 1$ & $2.73(1.34$ to 5.55$)$ \\
\hline
\end{tabular}

Table 3 Odds ratios for symptom category by exposure community

\begin{tabular}{|c|c|c|c|c|}
\hline \multirow[b]{3}{*}{ Symptom category } & \multicolumn{2}{|l|}{ Frequency } & \multirow{2}{*}{\multicolumn{2}{|c|}{ OR $(95 \% C I)^{*}$}} \\
\hline & \multirow[b]{2}{*}{$\begin{array}{l}\text { Exposed } \\
(n=99)\end{array}$} & \multirow{2}{*}{$\begin{array}{l}\text { Unexposed } \\
\text { controls } \\
(n=89)\end{array}$} & & \\
\hline & & & $\begin{array}{l}\text { Asymptomatic } \\
\text { controls }\end{array}$ & $\begin{array}{l}\text { Non-specific } \\
\text { controls }\end{array}$ \\
\hline Asymptomatic & 30 & 47 & $1 \cdot 0$ & \\
\hline Non-specific & 26 & 28 & $1.56(0.76$ to 3.23$)$ & 1.0 \\
\hline Possible & 24 & 10 & $4.12(1.66$ to 10.20$)$ & 2.86 (1.08 to 7.61$)$ \\
\hline Probable & 19 & 4 & $9.93(2.87$ to 34.42$)$ & $6.17(1.70$ to 22.41$)$ \\
\hline
\end{tabular}

^Adjusted for age, sex, drinking, and smoking. nity reported spray plane sightings near their community in the preceding 15 days. Residents of the exposed community were also significantly more likely to report having been "drifted upon" from a spray plane (44\% $v 0.0 \%, \mathrm{P}<0.001$ ), having crossed recently sprayed fields $(57.1 \% \vee 2.0 \%, \mathrm{P}<0.001)$, having eaten home grown food $(65 \% v 0.0 \%$, $P<0.001$ ), and having felt ill after the passage of a spray aeroplane $(41.4 \%$ v $0.0 \%$, $\mathrm{P}<0.001)$. The AChE concentration was significantly lower in the exposed than in the control community, mean 4.9 IU $v 5.3$ IU, (mean difference $95 \%$ CI 0.18 to 0.72 ). Additionally a significantly higher percentage of subjects in the exposed community reported at least one symptom during the interview ( $87 \%$ v 53\%, $\mathrm{P}<0.001$ ).

Table 2 shows the prevalence of acute symptoms reported as having occurred during the preceding 15 days, the prevalence of chronic symptoms (no time specified) assessed from the Spanish language version of Q-16, and the odds ratios for residence in the exposed community. Most acute symptoms and modified Q16 symptoms showed significant associations with residence in the exposed community. For residents of the exposed community the odds ratio was 18 (95\% CI 6.8 to 46) for having four or more positive symptoms and 4.8 (95\% CI 2.3 to 10$)$ for having one to three symptoms. When symptom category was examined according to community (table 3), an obvious pattern of increasing odds ratio with increasingly specific symptom categories was noted. Stratified analysis by sex and formal tests for interaction by sex (data not shown) indicated no preponderance of association in males or females.

We obtained limited information on the use of pesticides from several owners and operators of the fields adjacent to the exposed community. The following pesticides could be identified as having been applied to the adjacent fields during the 1990 season: methylparathion; two pyrethroids; cypermethrin; $\lambda$-cyhalothrin, an insect growth regulator; and a locally prepared mixture of organophosphate and pyrethroid. Not all contacted owners cooperated with our requests for information, and the pesticides mentioned were only those about which we could obtain some information. Data on the amount of pesticide applied were not made available to us.

\section{Discussion}

Exposure of humans to pesticide is a major concern for populations in agricultural communities worldwide. This cross sectional study of environmentally exposed and control communities showed significant differences in reporting symptoms and $\mathrm{ChE}$ concentrations. Although the lack of subject blinding to the purpose of the study may have contributed to overreporting of symptoms on the part of the exposed community members, a strong association between exposure and increasingly specific symptom clusters was noted for symptoms known beforehand to be associated 
with overexposure to organophosphate pesticide. Cholinesterase concentrations provided a biological index of relative exposure and thus offer some support to the validity of exposure classification by community.

This study has several important limitations. We used a single cross sectional assessment of symptoms because a longitudinal study was not feasible. We did not directly collect socioeconomic or education information from subjects, but instead relied on information from Ministry of Health personnel and a community organisation to help select comparable communities. Socioeconomic differences may have influenced overall reporting of symptoms but they are unlikely to have influenced the distribution of subjects according to the more specific symptom clusters.

We measured AChE to document exposure differences with a relatively new field method which has been shown to be more accurate than those previously used..$^{24} \mathrm{AChE}$ has a wide range of normal values in human populations and is affected by the number of red cells in a given sample. Interpretation of AChE differences is limited, however, because we did not have pre-exposure baselines and were unable to measure haemoglobin concentrations to adjust AChE values because a reliable, portable haemoglobin measurement method was not available. None the less, we found that one of the most common causes of anaemia in Nicaragua at the time, malaria, was reported equally between the two communities, and differences in factors which could have influenced nutrition were probably minimised by selecting socioeconomically similar communities.

We verified that some organophosphate pesticides that inhibit $\mathrm{ChE}$ were used on the fields surrounding the exposed community; however, we have no information on quantities of pesticides applied other than knowledge of traditional pesticide use in Nicaraguan cotton growing. ${ }^{12}$ Quantitative measures of exposure assessment-such as urinary metabolites or exposure sampling - could not be obtained feasibly in this instance, although the lower mean AChE concentrations in the exposed community supported our use of community of residence as a proxy for drift exposure.

Another obvious limitation is the small size of the study which constrains statistical precision of estimates of effect. Our method of subject selection was by random selection from a community list thus avoiding volunteer bias. We excluded subjects with direct work exposure to pesticides which minimised confounding from occupational exposure. We did not obtain information about use of pesticides at home but have no reason to suspect that it would differ significantly between the communities.

Importantly, we focused on only the most acutely toxic pesticides (organophosphates) due to the availability of a relatively specific test of effect, AChE. Although not evaluated, exposure to other aerially applied pesticide mixtures known to be routinely applied to cotton in this area of Nicaragua is undoubtedly greater in the exposed community. Our results are in agreement with those of Richter et al ${ }^{13}$ in Israel, but our findings show an even stronger effect on concentrations of $\mathrm{ChE}$ in the population. The results of our study suggest that residence in a community with apparently significant drift exposure correlates strongly with the increasing frequency and specificity of symptoms. Because of the large numbers of people worldwide who experience similar chronic residential exposure, the results should motivate efforts at replication of this study in other settings, with more complete exposure evaluation.

We gratefully acknowledge the contributions of Araceli Gutierrez for her attention to detail in data entry and assistance in coordination, Dr Rafael Amador for generously lending his modified Q-16 for use in this study, and to Dr Carlos Tuarez for his assistance in data collection.

1 Murray D. Cultivating crisis: the human cost of pesticides in Latin America. Austin: University of Texas Press, 1994. Sweezy M, Murray D, Daxl R. Nicaragua's revolution in pesticide policy. Environment 1986;28:6-9,29-36.

3 Cole D, McConnell R, Murray D, Pacheco A. Pesticide illness surveillance: the Nicaraguan experience. Bull Pan Am Health Organ 1988;22:119-32.

4 Keifer M, McConnell R, Pacheco A. Pesticide poisonings in Nicaragua: 1986-90. Rev Epidemiol Sante Publique. 1992;40(suppl 1):150.

5 McConnell R, Hruska J. An epidemic of pesticide poisoning in Nicaragua: implications for prevention in developing countries. Am $\mathcal{F}$ Public Health 1993;83:1559-62.

6 Wesseling C, Castillo L, Elinder C. Pesticide poisonings in Costa Rica. Scand $f$ Work Environ Health 1993;19: 227-35.

7 Draper W, Gibson R, Street J. Drift from transport subsequent to a commercial aerial application of carbofuran: an estimation of potential human exposure. Bull Environ Contam Toxicol 1981;26:537-43.

8 Goldman L, Mengle D, Epstein D, Fredson D, Kelly K, Jackson RJ. Acute symptoms in persons residing near field treated with the soil fumigants methyl bromide and chloropicrin. West f Med 1987;147:95-8.

9 Barnes C, Lavy T, Mattice J. Exposure of non-applicator personnel and adjacent areas to aerially applied propanil. Bull Environ Contam Toxicol 1987;39:126-33.

10 Ames R, Howd R, Doherty L. Community exposure to paraquat drift. Arch Environ Health 1993;48:47-51.

11 Hayes W, Dixon E, Batchelor G, Upholt W. Exposure to organic phosphorus sprays and occurrence of selected symptoms. Public Health Rep 1957;72:787-94.

12 Summerford T, Hayes W, Jonston J, Walker K, Spillane J. Cholinesterase response and symptomatology from exposure to organic phosphorus insecticides. American Medical Association Archives of Industrial Hygiene 1953;7: 383-98.

13 Richter E, Chuwers P, Levy Y, Gordon M, Grauer F, Marzouk J, et al. Health effects from exposure to organophosphate pesticides in workers and residents in Israel. Isr f Med Sci 1992;28:584-98.

14 Richter E, Rosenvald Z, Kaspi L, Levy S, Gruener N. Sequential cholinesterase test and symptoms for monitoring organophosphate absorption in field workers and in persons exposed to pesticide spray drift. Toxicol Lett 1986;33:25-35.

15 Namba T, Nolte C, Jackrel J, Grob D. Poisoning due to organophosphate insecticides: acute and chronic manifestations. Am $\mathcal{F}$ Med 1971;50:475-92.

16 Magnotti R, Dowling K, Eberly P, McConnell R. Field measurement of plasma and erythrocyte cholinesterases. Clin Chim Acta 1988;315:315-32.

17 Amador R, Lundberg I, Escalona E. Development of a questionnaire in Spanish on neurotoxic symptoms. $A m \mathcal{F}$ Ind Med 1995;28:505-20

18 Hogstedt C, Andersson K, Hane M. A questionnaire approach to monitoring of early disturbances in central nervous functions. In: Aitio A, Riihimaki V, Vainio $H$, eds. The biological monitoring and surveillance of workers eds. The biological monitoring and surveillance of workers
exposed to chemicals. Washington, DC: Hemisphere, 1984:272-87.

19 Bhu N, Khabya B, Mendiratta B. Chronic organophosphorus poisoning in pesticide workers. Ind $\mathcal{f}$ Pub Health 1976;2:62-7.

20 McConnell R, Pesticides and related compounds. In: Rosenstock L, Cullen M. eds. Textbook of occupational and environmental medicine. Philadelphia: Saunders, 1994:847-65.

21 Legaspi J, Zenz C. Occupational health aspects of pesticides. In: Zenz C, ed. Occupational medicine. St Louis: Mosby, 1994:617-53.

22 Dixon WJ. BMDP statistical software. Berkely: University of California Press, 1992.

23 Hosmer DW, Lemeshow S. Applied logistic regression. New York: Wiley, 1989.

24 McConnell R, Magnotti R. Screening for insecticide overexposure under field conditions: a reevaluation of the tintometric cholinesterase kit. Am $\mathcal{f}$ Public Health 1994;84: 479-81. 